\title{
O EMPREENDEDORISMO E A EVOLUÇÃO ECONÔMICA DAS NAÇÕES: IDÉIAS E CONCEITOS PARA SEU SUCESSO NO BRASIL
}

\author{
Ivam Ricardo Peleias ${ }^{1}$ \\ Amauri Jorge Macedo da Silva ${ }^{2}$ \\ Iolanda do Couto Guimarães ${ }^{3}$ \\ Lúcio de Souza Machado 4 \\ João Bosco Segreti 5
}

\begin{abstract}
Resumo: Este artigo apresenta uma análise comparativa entre os dados das pesquisas sobre empreendedorismo realizadas pelo Global Entrepreneurship Monitor (GEM) em 2002 e 2003. O objetivo principal é contribuir para melhor compreender o movimento empreendedor brasileiro, tendo como referência as experiências internacionais, e oferecer novas formas de abordagem a serem consideradas por possíveis empreendedores. A princípio, esta pesquisa - exploratória, documental, bibliográfica, descritiva e qualitativa - procura evidenciar que o empreendedorismo pode ser entendido pelo estudo de exemplos ocorridos ao longo da história. Durante esse relato histórico, é introduzido 0 conceito de inovação, que é um elemento fundamental no processo empreendedor. Na seqüência, 0 trabalho busca demonstrar, por meio da análise comparativa, algumas semelhanças entre o processo empreendedor brasileiro e o de outros países, apresenta e discute o conceito de redes sociais como instrumento para viabilização de empreendimentos, e finaliza com a apresentação do conceito de agrupamento de empresas, suas vantagens e requisitos para uma implementação eficaz.
\end{abstract}

Palavras chave: Empreendedorismo. Inovação. Redes Sociais. Agrupamentos de Empresas.

\section{INTRODUÇÃO}

Ao longo de anos e gerações uma questão se coloca: quais as perspectivas para os seres humanos e seus descendentes em relação ao futuro. Todas as gerações fizeram essa pergunta em algum momento e, por mais que se tente mostrar que há maiores obstáculos na atualidade, mantidas as proporções, nota-se que as preocupações se mantêm no decorrer da história. As premissas podiam ser diferentes e as opções mais restritas, mas a mesma pergunta se perpetua: o que fazer para garantir um futuro melhor para os seres humanos e seus descendentes. Em algum momento de suas vidas, as pessoas "empreendem" algum projeto para garantir um futuro melhor para si e, quando possível, para as futuras gerações.

É preciso se ter em mente que empreender não é obrigatoriamente uma atitude individual como a criação de um negócio próprio. Pode também ser 0 ato de alguém atuar como um agente de

\footnotetext{
1 Programa de Mestrado em Ciências Contábeis, FECAP e PUC, São Paulo, SP. E-mail: ivamrp@fecap.br,

2 Mestrando em Ciências Contábeis, FECAP, São Paulo, SP. E-Mail: amauri.macedo@uol.com.br

3 Programa de Mestrado em Ciências Contábeis, FECAP, São Paulo, SP. E-Mail: iolandacouto@hotmail.com

${ }^{4}$ Programa de Mestrado em Ciências Contábeis, FECAP, São Paulo, SP. E-Mail: audifloresta@terra.com.br

${ }^{5}$ Programa de Mestrado em Ciências Contábeis, FECAP, São Paulo, SP. E-Mail: segreti@fecap.br
} 
mudança dentro de uma organização, seja em uma empresa particular, em um órgão de governo ou em uma instituição de ensino.

Um problema para muitos países é gerar "riqueza" para que as pessoas tenham uma vida digna. Aqui o termo riqueza está relacionado a uma condição econômica capaz de suprir as necessidades essenciais do ser humano: alimentação, moradia, educação e saúde. Por mais que tentem, os governos não conseguem arcar sozinhos com os custos de manutenção dessas necessidades para todos os cidadãos. Assim, é possível deduzir que os governos e os cidadãos desses países tenham interesse em fomentar o empreendedorismo. 0 presente artigo procura, por meio de uma comparação com a história e a tendência empreendedora mundial, estudar e melhor compreender o posicionamento brasileiro em relação a esse tema.

\section{UMA VISÃO HISTÓRICA DA PRÁTICA EMPREENDEDORA}

Muitas vezes, o termo empreendedor é associado ao criador de uma nova empresa, que, de alguma forma, promove inovações em seu setor de atuação. A partir dessa ótica, é possível reconstruir a atividade econômica ao longo da história. Baumol (2004) oferece uma retrospectiva histórica do empreendedorismo, apresentada de forma resumida a seguir.

Em muitas sociedades, a inovação técnica e tecnológica na área militar era o caminho efetivo para o sucesso, o poder e a riqueza. Durante grande parte da história, qualquer indivíduo que criasse um negócio ou promovesse uma inovação produtiva estaria em desgraça. Como contraponto a esse argumento, muitas pessoas, inclusive os empreendedores, tinham por objetivo alcançar a riqueza, 0 poder e o prestígio. Na verdade, um empreendedor procura escolher uma atividade que ofereça maiores chances de atingir tais objetivos, muitas vezes, independentemente das conseqüências sociais que tal atitude venha a apresentar.

É preciso considerar tal observação com ressalvas, pois os padrões morais tendem a se adaptar às práticas e oportunidades correntes. Significa que atividades, hoje, consideradas antiéticas poderiam ter sido normais ou recomendadas no passado. Como exemplos houve a Roma antiga e a China medieval, sociedades pródigas em inventos militares e não militares, nas quais a busca pela riqueza e poder eram aceitáveis e desejáveis, assim como nas sociedades capitalistas. Essa riqueza e poder eram geralmente obtidos por agressão militar, usura e suborno, meios de acumulação de bens aceitáveis na época. Séculos antes de Colombo, os chineses inventaram o processo de impressão, os relógios de água, a pólvora, a porcelana, os fósforos, a escova de dente, as cartas de jogar e muito mais. Mas foi a partir de Colombo que tais inventos geraram crescimento econômico, quando explorados comercialmente pela civilização ocidental.

Esse padrão de ética em relação à riqueza e ao poder manteve-se vivo por muito tempo, reforçado por penalidades para os desvios considerados morais. Exemplificando, um nobre perderia seus títulos se exercesse alguma atividade manual ou entrasse no sórdido negócio do comércio, pois, nas economias medievais da Europa, a posse de terras era a forma mais respeitável e desejada de investimento.

Tais atitudes mudaram, primeiro na Inglaterra e depois na França, à medida que as pressões financeiras cresciam por meio de vários eventos históricos não relacionados entre si. 0 primeiro foi 0 crescente custo de preparação militar quando uma nação agressiva precisava superar o poderio militar de seu rival. A cada passo de um rei, seus rivais tinham que, pelo menos, igualar suas forças às do agressor. A segunda causa diz respeito às pesadas despesas, pré-requisito de status para os membros 
da nobreza. Essas pressões financeiras tinham que ser resolvidas, por isso, os nobres e mesmo os reis passaram a exercer atividades produtivas. Primeiro investiram no comércio, depois na produção direta. Como conseqüência, essas atividades começaram a se tornar respeitáveis.

$\mathrm{Na}$ Inglaterra, após suas vitórias na guerra das rosas, o Rei Eduardo IV investiu substancialmente na exportação de lã, roupas, lata e, posteriormente, na importação. Sua atitude foi seguida por muitos nobres, os quais passaram a praticar tais atos sem se preocupar com as eventuais implicações morais e legais.

Além da propensão a denegrir a imagem dos empreendedores, havia, naquela época, outros fatores que cerceavam a ação empreendedora. Por exemplo, existia a possibilidade da expropriação dos bens, o que desencorajava os investimentos em ativos, os quais podiam ser facilmente observados e requisitados. Em algumas sociedades, em última instância, tudo pertencia ao monarca, que muitas vezes era induzido a pôr a teoria em prática, levando para si qualquer propriedade acessível, especialmente quando as pressões financeiras eram grandes ou quando 0 ativo era atraente $\mathrm{e}$ lucrativo.

Tal situação perdurou até o momento em que se passou a respeitar as leis e os contratos. Essa mudança ocorreu de forma lenta e gradual nas sociedades de então. Na Inglaterra, por exemplo, os reis foram forçados a aceitar demandas cada vez maiores da nobreza, de forma a protegê-los de uma expropriação arbitrária.

A posição social, econômica e política do empreendedor elevou-se gradativamente e a atividade empreendedora, que traz a oportunidade para o acúmulo de riqueza, tornou-se um incentivo irresistível para que surgisse o empreendedor moderno. Esse processo, no entanto, só ganhou escala com o surgimento e crescimento das economias capitalistas.

Apesar de suas limitações e imperfeições, a economia capitalista, como demonstrado por Marx e Engels no início de 1848, por meio do Manifesto do Partido Comunista, teve ao menos um grande crédito a seu favor: os abundantes registros de produção, inovação e crescimento econômico Marx e Engels (apud BAUMOL, 2004) escreveram:

A burguesia (leia-se o capitalismo) não pode existir sem constantemente revolucionar os instrumentos de produção [...] A conservação dos antigos modos de produção, ao contrário, foi condição para a existência das primeiras classes industriais. A burguesia criou forças mais produtivas em 100 (cem) anos do que todas as gerações precedentes juntas.

Ao longo de 1.500 anos, antes da Revolução Industrial, as taxas de crescimento foram estimadas como próximas de zero, embora tenha ocorrido algum crescimento perto do século X. Com 0 advento do capitalismo na Inglaterra, a partir do século XVIII, o Produto Interno Bruto (PIB) per capita teve crescimento estimado entre $20-30 \%$. No século XIX, esse número ficou em torno de $200 \%$. No século XX, nos Estados Unidos, estimou-se um crescimento da ordem de 700\%.

Finalizando o relato das idéias de Baumol (2004), cabe destacar que, em economias modernas que não operaram em regime de livre mercado, as instituições não incentivavam o vigor e a expansão do empreendedorismo produtivo. Um exemplo clássico disso se deu na União Soviética, onde, apesar da profusão de cientistas e engenheiros responsáveis por muitas invenções, o processo de inovação (aqui considerado num contexto que contemple a ampla disseminação e uso) teve baixo desempenho. Aparentemente, as razões não estavam nas atitudes do governo para com os empreendedores e seu status na sociedade, mas no sistema de compensação que desencorajava atividades empreendedoras vigorosas, pois não havia recompensa pelo sucesso, apesar dos riscos a serem assumidos no processo. 
Ao corroborar a tese de que para o empreendedorismo produtivo obter espaço na sociedade, é preciso que a sua liderança também seja empreendedora, Pinto (2000) destaca a capacidade de multiplicação e intensificação da atividade empreendedora nos Estados Unidos, relacionada ao grau de empreendedorismo de seus presidentes ao longo da história. Pinto (2000) observa que: quanto mais empreendedor é o presidente, maior é o crescimento da economia.

Ao analisar o trabalho realizado, em 2003, pelo Global Entrepreneurship Monitor (GEM), grupo que pesquisa o empreendedorismo em 37 países, tem-se uma clara idéia da situação sócio-econômica brasileira em relação a vários países do mundo: desenvolvidos, em desenvolvimento e subdesenvolvidos. É 0 que se observa na tabela 1.

\section{Tabela 1 - Características da força de trabalho e emprego dos países}

\begin{tabular}{|c|c|c|c|c|c|c|c|c|c|c|}
\hline 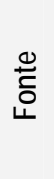 & Indicadores & $\begin{array}{l}\frac{0}{0} \\
\frac{\pi}{0} \\
\frac{\pi}{5}\end{array}$ & $\stackrel{\circ}{\frac{1}{\alpha}}$ & $\mathbf{z}$ & 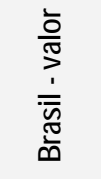 & 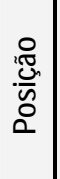 & 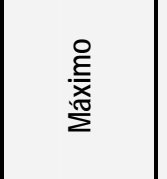 & $\frac{\overline{0}}{\frac{\pi}{\pi}}$ & 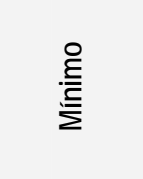 & $\frac{\overline{0}}{\frac{\pi}{\pi}}$ \\
\hline (2) & PIB/ (PPA) - pessoa empregada & US\$ & 2000 & 27 & 16.493 & 25 & E.U.A. & 69.193 & China & 6.884 \\
\hline (4) & Mudança \% PIB real por pessoa empregada & $\%$ & 2000 & 27 & $-5,78$ & 27 & Noruega & 15.983 & Brasil & $-5,78$ \\
\hline (1) & PIB (PPA) - pessoa empregada/hora & $\%$ & 2000 & 27 & 9,33 & 25 & Bélgica & 39,95 & China & 3,47 \\
\hline (2) & PIB (PPA) - pessoa empregada-agricultura & US\$ & 2000 & 26 & 52,96 & 24 & Reino Unido & 64.162 & China & 2.354 \\
\hline (2) & PIB (PPA) - pessoa empregada-indústria & US\$ & 2000 & 26 & 31.942 & 23 & Holanda & 89.565 & China & 15.084 \\
\hline$(2)$ & PIB (PPA) - pessoa empregada-serviços & US\$ & 2000 & 26 & 17.255 & 25 & Bélgica & 68.813 & China & 8.512 \\
\hline (2) & Horas trabalhadas-ano & Número & 2000 & 27 & 1.931 & 9 & Chile & 2.244 & França & 1.587 \\
\hline (3) & Taxa de desemprego & Número & 2001 & 27 & 9,60 & 6 & $\begin{array}{l}\text { África do } \\
\text { Sul }\end{array}$ & 29,5 & Islândia & 1,40 \\
\hline (3) & Força de trabalho total-milhões & Número & 2001 & 26 & 85,26 & 3 & China & 717,45 & Islândia & 0,16 \\
\hline (3) & Partic. Feminina na força de trabalho & $\%$ & 2001 & 24 & 41,09 & 19 & Islândia & 49,81 & Chile & 34,04 \\
\hline (3) & $\begin{array}{l}\text { Desempenho da força de trabalho idade }>=25 \\
\text { anos- } \% \text { de desempenho total }\end{array}$ & $\%$ & 2001 & 23 & 51,40 & 1 & Brasil & 51,4 & Alemanha & 12,80 \\
\hline (1) & Particip. setor público no total do emprego & $\%$ & 2000 & 27 & 11,10 & 24 & Noruega & 37,5 & Singapura & 3,60 \\
\hline & $\begin{array}{l}\text { (1) The World Competitiveness Yearbook } \\
\text { titiveness Yearbook 2001, Institute for Man } \\
\text { nic Outlook Database (april, 2003) }\end{array}$ & 1 & Mal & & & & MD & & rld & \\
\hline
\end{tabular}

Fonte: GEM (2003, p. 15)

A tabela 1 revela índices positivos para o Brasil em comparação a outras economias. Apesar de ocupar posições que fazem menção à relação pessoas/PIB, que vistos de forma bruta o colocam em situação intermediária (entre $23^{\circ}$ e $27^{\circ}$ ), quando comparados à realidade de outros países emergentes e, principalmente, quando verificada sua evolução no tempo, nota-se avanços significativos rumo a uma melhor situação econômica da população.

Um dado chama a atenção nesse estudo: a participação das mulheres na força de trabalho disponível no país. É um número positivo que revela uma evolução cultural e social que leva o Brasil rumo à situação de economias de primeiro mundo. Porém, um dado preocupante é a taxa de desemprego entre jovens abaixo de 25 anos. Esse dado, por si só, demonstra o quanto o governo e a sociedade devem estar atentos à necessidade de fomentar o empreendedorismo no país para que essa mão-de-obra possa ser absorvida. 
Ao tentar criar estratégias, a sociedade e o governo não devem entender que os jovens precisem, obrigatoriamente, ser induzidos a abrir novos negócios. Esse princípio vale para todos os que tenham boas idéias, que visualizem uma boa oportunidade, de forma que, ao tentar explorá-la, empreguem o máximo possível de pessoas, reduzindo a ociosidade que, ao não ser absorvida, pode gerar graves problemas sociais, colocando em risco a estrutura sócio-econômica existente.

Nesse sentido, o governo tem um importante papel, pois o primeiro passo para indução ao empreendedorismo é uma estrutura tributária e legal simples e objetiva, cabendo ao restante da sociedade a tarefa de exercitar sua criatividade em prol das oportunidades.

Porém, ao se analisar a tabela 2, nota-se que essa não é a postura do Brasil, que vem revelando-se ineficaz no que diz respeito à criação de condições que incentivem o empreendedorismo. Mudar esse panorama requer a revisão das estruturas trabalhistas, tributárias e políticas do País. 0 Brasil precisa agir prontamente para reverter o quadro de desemprego crescente que lhe assola desde que passou a encarar mais seriamente a necessidade de se tornar competitivo mundialmente. A globalização obriga que não mais se pense individualmente.

Tabela 2 - Custos regulatórios e intervenção econômica/atuação do Estado

\begin{tabular}{|c|c|c|c|c|c|c|c|c|c|c|}
\hline ठัँ & Indicadores & : & 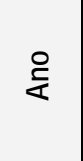 & $\mathbf{z}$ & 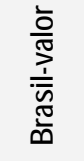 & 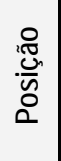 & 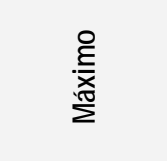 & $\frac{\overline{0}}{\frac{\pi}{\sigma}}$ & 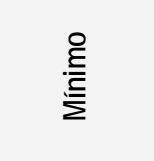 & $\frac{\overline{0}}{\frac{\pi}{\pi}}$ \\
\hline (1) & Permissões para iniciar novo negócio & Número & & 27 & 7 & 3 & Itália & 10 & Hong Kong & 2 \\
\hline (1) & Dias para iniciar negócio & Número & 1995 & 27 & 60 & 4 & Itália & 105 & Islândia & 5 \\
\hline (1) & $\begin{array}{l}\text { Procedimentos - registrar empresa } \\
\text { nascente }\end{array}$ & Número & 1995 & 27 & 15 & 3 & Itália & 16 & Canadá & 2 \\
\hline (2) & Custos da seguridade social-\% do PIB & $\%$ & 2000 & 27 & 37,30 & 2 & França & 48,43 & China & 0 \\
\hline (2) & $\begin{array}{l}\text { Taxa de contribuição social do } \\
\text { empregador-\% do PIB }\end{array}$ & $\%$ & 2000 & 27 & 10,68 & 3 & Suécia & 11,75 & Austrália & 0 \\
\hline (3) & Tributação máxima sobre a renda & $\%$ & 1999 & 26 & 28,00 & 24 & Holanda & 60 & Hong Kong & 17 \\
\hline (2) & $\begin{array}{l}\text { Arrecadação sobre capital e propriedade- } \\
\% \text { do PIB }\end{array}$ & $\%$ & 1999 & 27 & 1,90 & 14 & Reino Unido & 3,92 & Hong Kong & 0,1 \\
\hline (2) & $\%$ médio-tributação de lucros & $\%$ & 2002 & 26 & 25,00 & 22 & Alemanha & 41,6 & Hong Kong & 16 \\
\hline (2) & Subsídios governamentais - \% do PIB & $\%$ & 1998 & 23 & 0,45 & 21 & Suécia & 4,52 & Chile & 0,13 \\
\hline (1) & Certificações ISO / 1000 habitantes & Número & 1999 & 27 & 0,02 & 23 & Reino Unido & 1,00 & Chile & 0,00 \\
\hline (1) & $\%$ do PIB - Economia informal & $\%$ & 2000 & 26 & 33,40 & 2 & Tailândia & 37,50 & Suíça & 8,60 \\
\hline (1) & e trabalhadores na economia informal - \% & $\%$ & 2000 & 13 & 49,20 & 2 & Croácia & 70,00 & Canadá & 4,40 \\
\hline (1) & Retorno sobre ativos & Taxa & & 27 & 0,197 & 12 & E.U.A & 0,34 & Singapura & 0,06 \\
\hline (1) & Índice de corrupção BIRD-1=limpo & Índice $\mathrm{n}^{0 .}$ & & 27 & 0,328 & 23 & Dinamarca & 1,00 & Croácia & 0,16 \\
\hline (1) & Índice de corrupção ICRG-1=limpo & Índice $\mathrm{n}^{0 .}$ & & 27 & 0,4 & 22 & Holanda & 1,00 & China & 0,20 \\
\hline (1) & Eficácia governamental & Índice $\mathrm{n}^{0}$. & & 27 & $-0,22$ & 27 & Singapura & 2,08 & Brasil & $-0,22$ \\
\hline (1) & Eficácia legislativa & Índice $\mathrm{n}^{0 .}$ & & 24 & 1,61 & 19 & E.U.A. & 3,00 & China & 0,91 \\
\hline (1) & Instituições políticas fechadas $-0=$ =abertas & Índice $\mathrm{n}^{0 .}$ & & 11 & 3,00 & 8 & China & 7,51 & França & 0,21 \\
\hline (1) & $\begin{array}{l}\text { Média de direitos políticos 1972-1999- } \\
\text { 1=máxima }\end{array}$ & Índice no. & & 26 & 0,64 & 18 & E.U.A. & 1,00 & China & 0,03 \\
\hline (1) & Índice de direitos civis & Índice $\mathrm{n}^{0 .}$ & & 26 & 0,50 & 23 & E.U.A. & 1,00 & China & 0,17 \\
\hline (1) & Direito à propriedade & Índice $\mathrm{n}^{\mathrm{O}}$. & 1997 & 27 & 0,50 & 24 & E.U.A. & 1,00 & Croácia & 0,25 \\
\hline
\end{tabular}

Fonte: (1) Djankov, S., Silanes, F., Shelfer, A. (2001) The Regulation of Entry NBER Paper No. W7892; (2) IMD (2000) The World Competitiveness Yearbook 2002, Institute for Management Development, Switzerland; (3) World Bank (2000) World Development Indicators 2000, International Bank for Reconstruction and Development, Washington DC.

Fonte: GEM (2003, p.17) 


\section{METODOLOGIA DA PESQUISA}

Embora seja debatido há muito tempo, o empreendedorismo continua sendo um tema controverso. Muito se discute sobre o que seja uma pessoa empreendedora e quais as características que a definem; porém o empreendedorismo é mais amplo, abrangente e complexo. Tendo em vista essa situação, este artigo é de caráter exploratório, pois busca "reunir mais conhecimento e incorporar características inéditas, bem como buscar novas dimensões até então não conhecidas" (BEUREN, 2004, p. 81).

Por conta do caráter exploratório, os procedimentos de pesquisa adotados foram de natureza documental, bibliográfica e descritiva (APPOLINÁRIO, 2005), pelos quais se procurou abranger 0 máximo possível de material relevante sobre o tema. Para Marconi; Lakatos (1999) a pesquisa bibliográfica não é mera repetição do que foi dito ou escrito sobre um assunto, pois pode propiciar 0 exame de determinado tema sob um novo enfoque ou abordagem. Esse procedimento contribui para se chegar a conclusões muitas vezes inovadoras. Para Cervo; Bervian (2002, p. 66) "a pesquisa bibliográfica é meio de formação por excelência e constitui o procedimento básico para os estudos monográficos, pelos quais se busca o domínio do estado da arte sobre determinado tema."

Realizada a revisão histórica da prática empreendedora, será discutida a inovação, a qual, além de ser o dínamo do empreendedorismo, ainda vem sendo tratada de forma superficial na atualidade. Esta situação gera falsas expectativas sobre o tema, o que ajuda a deturpar o conceito de empreendedorismo junto ao grande público.

Ao abordar essa temática, 0 artigo procura discutir a importância das redes sociais como instrumento para viabilizar empreendimentos. Esse posicionamento procura demonstrar que negócios de sucesso nascem a partir de um amplo trabalho de pesquisa por parte dos que se propõem a empreender, independente do país, da cultura ou da situação econômica.

Para finalizar a discussão proposta, são apresentados os conceitos de agrupamentos de empresas. Os agrupamentos são uma importante alternativa para viabilizar empresas de pequeno e médio porte, a ponto de ser alvo de ações específicas de governos de países de economia forte e estável para a manutenção e geração de empregos. Essa alternativa é pouco comentada, incentivada e explorada nos países de economia mais frágil.

A abordagem adotada para este trabalho teve ainda um caráter qualitativo (APPOLINÁRIO, 2005), uma vez que o que se procura é um melhor conhecimento de determinado fenômeno social.

\section{A INOVAÇÃO COMO DÍNAMO DO EMPREENDEDORISMO}

O sentido atualmente difundido para o termo empreendedor ganhou papel mais relevante por meio de Schumpeter (1996), o qual, com o livro Capitalism, socialism and democracy, originalmente publicado em 1947, lançou seus conceitos em relação ao crescimento e a inovação. Para Schumpeter (1996), inovação é um processo iniciado com o nascimento de uma idéia até sua chegada ao mercado, na forma de um produto ou processo.

Um aspecto importante para o empreendedor produtivo é a existência de um mercado livre e competitivo ou, no mínimo, do interesse desse mercado por novas tecnologias, produtos e serviços, os quais ofereçam benefícios não vislumbrados até então. Para muitas sociedades, o empreendedor se tornou respeitável e assumiu atributos de heroísmo, é o caso de Henry Ford e Bill Gates, exemplos de dois momentos distintos da história recente. 
Apesar dos exemplos de Ford e Gates, muitas vezes, o empreendedorismo é associado a empresas pequenas, uma vez que os empreendedores são definidos como os criadores de novas empresas. Essa observação é importante para a investigação sobre o papel dos empreendedores no processo de inovação da economia.

Quando se procura mensurar os investimentos em pesquisa e desenvolvimento, nota-se que, a princípio, estes são realizados direta ou indiretamente por governos ou grandes empresas, que dificilmente se associam ao conceito de empreendedorismo. Sob a ótica da inovação, um fato a ser considerado em relação à participação das grandes empresas e dos governos em atividades de pesquisa e desenvolvimento é que, em geral, quando por eles fomentadas, essa atividade é limitada em razão de seus interesses e de sua percepção de risco, as quais acabam cerceando o poder de imaginação dos pesquisadores.

Schumpeter (1996) previu, em seus estudos, que se o processo de inovação fosse burocrático, o futuro dos empreendedores envolvidos seria limitado. Em razão disso, o empreendedor independente sempre terá um papel vital no processo de inovação, pois, por conceito, este vislumbra antes a oportunidade para em um segundo momento ponderar o risco.

Para se entender o termo invenções, Baumol (2004, p. 321) recomenda sua segmentação em dois tipos básicos:

a) as revolucionárias como a eletricidade e o circuito integrado, por exemplo;

b) as melhorias cumulativas como, por exemplo, as melhoras sucessivas dos computadores e dos automóveis.

Segundo Baumol (2004), muitos produtos podem não se enquadrar em nenhum dos dois tipos, ou, às vezes, algum produto pode apresentar cumulativamente as duas características. Entretanto, entender os reflexos de uma inovação é um ponto crucial para melhor caracterizar um empreendedor no ato de sua avaliação.

Ao analisar os casos de sucesso do mundo empresarial, nota-se grande conservadorismo em relação à pesquisa e desenvolvimento nas grandes empresas, o que, muitas vezes, em casos extremos, explica a sua descontinuidade. Como já comentado anteriormente, essas empresas tendem a se especializar na melhoria contínua de seus produtos, evitando os riscos do desconhecido que uma descoberta revolucionária acarreta.

Assim, as invenções revolucionárias são quase que naturalmente deixadas a cargo de empresas recém criadas, guiadas pelo empreendedorismo de seu proprietário. Um exemplo disso é a IBM que, nos anos 80, procurou desenvolver um sistema operacional para seus equipamentos. Ao ser apresentado o produto final, a Diretoria da época julgou que a empresa não deveria envidar esforços na área de softwares, mas sim na área de hardware. O inventor do sistema operacional foi liberado para fazer o uso que quisesse do produto e, com isso, surgiu a Microsoft.

Baumol (2004, p. 322) recorreu a um estudo recente da Small Business Administration (2003), que examinou mudanças técnicas por meio de patentes e definiu pequenas empresas como aquelas com menos de 500 empregados, para chegar a algumas conclusões que corroboram o pensamento acima:

a) pequenas empresas representam $1 / 3$ das empresas com maior número de patentes;

b) as inovações de pequenas empresas são duas vezes mais ligadas a pesquisa científica, sendo substancialmente mais voltadas para a alta tecnologia;

c) pequenas empresas são mais efetivas em produzir inovações de alto valor agregado; 
d) pequenas empresas que lançam patentes são treze vezes mais inovadoras por empregado do que empresas grandes e

e) a patente de pequena empresa tem pelo menos duas vezes mais probabilidade de estar entre $01 \%$ de patentes de maior impacto do que a patente de uma grande empresa.

Apesar das constatações levantadas por Baumol (2004), não se deve imaginar que só as pequenas empresas são capazes de inovar. A necessidade natural das grandes empresas de buscar a melhoria contínua dos seus produtos - medida em intervalos de tempo - revela inovações significativas, que, muitas vezes, acabam por revolucionar os mercados, abrindo novas oportunidades de negócios. Um exemplo disso são os computadores, os quais, após sucessivas melhorias, puderam se integrar a produtos que, na sua criação, tinham uma concepção de uso mais simples e menos funcional.

Além da ênfase dada à iniciativa privada até aqui, é preciso considerar, ainda, a necessidade da presença das universidades e dos governos no processo de inovação, os quais, por meio de sua estrutura, devem viabilizar um ambiente propício para o progresso tecnológico, principalmente pelo fomento à pesquisa básica, para que seja possível a aplicação futura da inovação ou o estímulo à aplicação de seus resultados.

Outro aspecto relevante do processo de inovação é a possibilidade do licenciamento voluntário de propriedades, largamente difundido no mercado, gerando ganhos substanciais a empresas que adotam tal procedimento. Isso ocorre em grandes e pequenas empresas, resultando em rápido crescimento e na eliminação de tecnologia obsoleta.

Ao se pensar em novos empreendimentos, a premissa de que esses sejam motivados pela criação de alguma inovação tecnológica - promovida pelo empreendedor - pode levar à conclusão de que 0 empreendimento surge da oportunidade, o que nem sempre é verdadeiro. Pesquisa realizada pelo GEM (2000, p. 20) revelou que as duas principais razões que levam indivíduos a participar em atividades empreendedoras são:

a) identificar uma oportunidade de negócios dentre as opções de carreira;

b) alternativa forçada para o início de um novo negócio, em função da inexistência ou existência de oportunidades insatisfatórias de trabalho.

A pesquisa do GEM analisou as atividades empreendedoras em 37 países e considerou oportunidades ou necessidades para iniciar um empreendimento. Dados revelaram que, dentre os países pesquisados, inclusive o Brasil, as nações que apresentam problemas de desemprego possuem maior volume de negócios gerados a partir da ação empreendedora. A pesquisa (2000, p. 21) evidenciou que, em relação aos empreendimentos realizados por necessidade, o Brasil aparece em $1^{\circ}$. lugar, com uma taxa de atividade empreendedora (TAE) de 7,5\%, seguido de perto por Argentina, Chile e China.

Quando a necessidade for a motivação principal, por mais que uma pessoa procure se cercar dos cuidados básicos na constituição de sua empresa, conceitos como competitividade, conhecimento sobre a área de atuação e oportunidade de mercado são secundários. A necessidade de uma renda faz com que as pessoas se arrisquem mais, até porque, na maioria dos casos, a opção é simplesmente continuar desempregada ou subempregada.

A incidência - maior ou menor - de empreendimentos criados por necessidade está diretamente relacionada ao momento econômico. Países com baixas taxas de desemprego e com uma economia mais forte possuem menor incidência de empreendimentos motivados pela necessidade. É o que se verificou com a pesquisa do GEM (2000, p. 20), que demonstrou que os empreendimentos realizados 
por necessidade, em países como França, Bélgica, Finlândia, Noruega e Dinamarca, ficaram em colocações opostas aos países considerados emergentes, os quais passam ou passaram recentemente por fortes modificações em seus cenários econômicos.

No Brasil, a vinculação entre o momento econômico e a supremacia dos negócios motivados por necessidade é muito clara. Além dessa constatação, verifica-se que o ímpeto empreendedor reconhecido em 2000 - momento em que a economia estava em franca expansão - não se manteve nos anos seguintes, marcados por constante retração econômica, conforme tabela 3.

Tabela 3 - Taxa de atividade empreendedora Brasil entre 2000 e 2003

\begin{tabular}{c|c|c|c|c}
\hline Ano & $\mathbf{2 0 0 0}$ & $\mathbf{2 0 0 1}$ & $\mathbf{2 0 0 2}$ & $\mathbf{2 0 0 3}$ \\
\hline$\%$ & 21,4 & 14,2 & 13,5 & 12,0 \\
\hline
\end{tabular}

Fonte: GEM (2003, p. 39)

Quando se procura identificar em que regiões do Brasil ocorrem concentrações de empreendedores, nota-se um vínculo direto entre a realidade econômica da região e o ímpeto empreendedor. Pois nas regiões que sofreram maior redução da atividade econômica, o volume de empreendedores mostrou-se mais elevado. É o que se verifica na tabela 4, que apresenta o percentual de empreendedores por região do País, em relação à população de cada região.

Tabela 4 - Estimativa do número de empreendedores por região do Brasil - 2000/2003

\begin{tabular}{c|c|c|c|c|c}
\hline Região & Norte & Nordeste & Sudeste & Sul & Centro-Oeste \\
\hline$\%$ & 23,0 & 14,0 & 14,0 & 19,0 & 13,0 \\
\hline
\end{tabular}

Fonte: GEM $(2003$, p. 40)

A tabela 4 revela que, para as regiões analisadas, quanto maior a carência de empregos, maior será a presença de espírito empreendedor na população local.

\subsection{AS REDES SOCIAIS COMO INSTRUMENTO DE VIABILIZAÇÃO DE UM EMPREENDIMENTO}

Para viabilizar um empreendimento não basta criatividade, competência e senso de oportunidade. Possuir um produto ou serviço inovador não significa uma vantagem competitiva. É necessário acesso ao mercado, e que este reconheça a necessidade e/ou a utilidade prática que tal produto ou serviço pode oferecer.

Para demonstrar que, mundialmente, os empresários acessam as pessoas em suas redes de relacionamento para discutir o estabelecimento e a administração de um negócio, será usada a pesquisa realizada por Greve; Salaff (2003) em quatro países. Esse trabalho estudou as atividades de empresários ao longo de três fases de estabelecimento de uma empresa: a de estudo da oportunidade, identificada como de motivação; a de planejamento do empreendimento e a do estabelecimento do empreendimento.

O trabalho de Greve; Salaff (2003) abrangeu as respostas de 213 empresários norteamericanos, obtidas junto ao Research Triangle Council for Entrepreneurial Development, de Durham, 
Carolina Norte; de 52 empresários italianos, obtidas pelo curso de empreendedorismo da Universidade de Bocconi, em Milão; de 261 empresários suecos, obtidas por associações para pequenas empresas em vários centros urbanos e de organizações que oferecem cursos de empreendedorismo; e de 62 empresários noruegueses, obtidas por cursos de empreendedorismo realizados em torno de 2 cidades no oeste da Noruega.

Essa pesquisa revelou que os empresários constroem redes de relacionamento que variam a cada fase do empreendimento. No planejamento, os empresários conversam com mais pessoas do que nas fases posteriores do negócio. Essa atitude é salutar pela possibilidade de muitos negócios serem idealizados a partir da visão do empreendedor, sem considerar sua aplicabilidade ao mercado, sua viabilidade econômica ou a existência de concorrentes reais ou potenciais.

De forma ideal, um empreendedor deveria ter em mente que muitas informações - necessárias ao planejamento de uma atividade - carecem de validação, de maior detalhamento por parte de terceiros que, por não estarem envolvidos, poderão lançar opiniões isentas.

A pesquisa de Greve; Salaff (2003) revelou que, em todas as fases, os familiares se fazem presentes nas redes de relacionamento dos empresários, em especial, entre os que assumiram firmas existentes. Um ponto relevante observado durante a pesquisa foi o fato de que as mulheres têm maiores dificuldades para manter relacionamentos familiares, principalmente, quando assumem uma firma existente. Sobre esse aspecto, há verdadeiro mito em relação às empreendedoras. A pesquisa revelou que, para muitos, as mulheres não têm experiência, interesse ou capacidade para ser proprietárias de negócios, em particular, os de grande porte. A simples manutenção da rede de relacionamentos envolve preconceitos quando as empreendedoras são do sexo feminino.

O trabalho de Greve; Salaff (2003) ainda revelou que - em todos os países abrangidos pela pesquisa - os empresários experientes têm os mesmos padrões que os novatos na rede de relacionamentos. A única diferença observada nesses países foi em relação ao tamanho das redes de discussão e ao tempo gasto nelas.

Menzies; Diochon; Gasse (2004) demonstraram o resultado de uma pesquisa realizada no Canadá entre 2000 e 2001, na qual observaram que as empreendedoras não diferem dos homens no que diz respeito ao engajamento no empreendimento, disposição em fazê-lo crescer e manutenção da rede de relacionamentos. Apesar desse resultado, observou-se que havia poucas mulheres nas áreas de engenharia e computação e maior concentração feminina na área da saúde. O estudo revelou que as mulheres pouco recorriam a cursos para empreendedores e se associavam mais aos familiares do que os homens. Um aspecto importante, demonstrado nesse estudo, é que equipes de trabalho formadas por homens e mulheres apresentaram maior rentabilidade do que as compostas por membros do mesmo sexo.

As redes de relacionamento têm diversas propriedades úteis para os empresários, tais como a capacidade de gerar informações cruciais e recursos de outros empresários já estabelecidos, o que minimiza as chances de fracasso da empreitada. Outro ponto a destacar é a possibilidade de, a partir dessas conversas, o empreendedor conseguir identificar o posicionamento a ser adotado para seu empreendimento.

Uma observação comum é a de que os empresários de muitos países são considerados individualistas. Esse aspecto, segundo Greve; Salaff (2003), não pode ser tido como negativo, pois os empresários individualistas possuem uma característica inovadora. De acordo com Tiessen (1997), os empresários coletivistas conseguem mobilizar recursos para fazer as empresas funcionar, mas essas características podem ser obtidas de um bom gerente e não obrigatoriamente de um empresário.

A análise realizada permite concluir que as relações sociais desempenham um papel importante no estabelecimento de uma empresa, uma vez que os empresários usam seu capital social 
para acessar recursos em cada fase do processo de estabelecimento, independentemente do país em que estejam estabelecidos.

Quando se procura verificar a realidade do empreendedorismo no Brasil em relação ao resto do mundo, nota-se uma crescente participação das mulheres. Em 2003, o Brasil possuía 14,2\% de homens empreendedores, 0 que lhe conferia a $7^{a}$ colocação no mundo. Entre as mulheres, este percentual chegou a 11,7\%, levando o Brasil a $4^{a}$ posição (GEM 2003). A tabela 5 evidencia a evolução dessa participação com maior clareza no cenário brasileiro.

Tabela 5 - Participação no empreendedorismo - homens x mulheres - 2000/2003

\begin{tabular}{l|c|c|c|c}
\hline & $\mathbf{2 0 0 0}$ & $\mathbf{2 0 0 1}$ & $\mathbf{2 0 0 2}$ & $\mathbf{2 0 0 3}$ \\
\hline Homens - \% & 71,0 & 71,0 & 58,0 & 54,0 \\
\hline Mulheres - \% & 29,0 & 29,0 & 42,0 & 46,0 \\
\hline
\end{tabular}

Fonte: GEM (2003, p. 31)

Os dados da tabela 5 demonstram uma configuração típica de países desenvolvidos. Considerando que a evolução social do Brasil é marcada por um velado preconceito em relação às minorias, a ocorrência de tal fenômeno indica um melhor preparo e uma menor discriminação à mulher do que se poderia esperar.

\subsection{AGRUPAMENTOS DE EMPRESAS: ALTERNATIVA PARA VIABILIZAR EMPRESAS DE PEQUENO E MÉDIO PORTE}

No início deste trabalho, foi apresentado um apanhado histórico do empreendedorismo, com destaque para a importância do Estado, seus líderes e a necessidade de adaptação de valores que a sociedade tem que estar disposta a encarar para encorajar o espírito empreendedor. Posteriormente, observou-se a importância da rede de relacionamentos para o empreendedor. Neste item, procurar-seá demonstrar uma forma alternativa para a viabilização de empresas de pequeno e médio porte, 0 agrupamento de empresas a partir de idéias desenvolvidas por Van Dijk; Sverrisson (2003).

Em geral, quando se aborda o agrupamento de empresas de pequeno e de médio porte, temse em mente um quadro ideal, no qual são alcançadas as economias de escala e de escopo semelhantes às observadas por empresas de grande porte. O que se busca é o melhor uso da mão de obra, menor necessidade de investimentos em relação ao custo da tecnologia requerida para a expansão / manutenção dos negócios, maior disponibilidade de informações, maior proteção contra ameaças de natureza econômica, financeira e legal, dentre outras. O agrupamento de empresas estabelece a proximidade física e, por conseqüência, oportunidades de colaboração entre as organizações. Ressalta-se, no entanto, que o nível dessa proximidade depende do contexto em que 0 agrupamento é estabelecido.

Após várias conjecturas, Van Dijk; Sverrisson (2003) definem os agrupamentos como redes relativamente densas de empresas e organizações, que possuem cadeias de valores conectadas, não necessariamente por meio de transações econômicas. A partir de uma extensa revisão bibliográfica acerca de agrupamentos, os autores concluíram que, para obter sucesso, todo o agrupamento deve possuir, no mínimo, as seguintes características: 
a) relativa proximidade espacial dos empreendimentos;

b) alta densidade de atividade econômica;

c) presença de muitas empresas cuja atividade seja igual, similar ou subsidiária;

d) possibilidade de atuação entre os empreendimentos por subcontratação (vertical);

e) algum grau de especialização e

f) possibilidade de atuação entre os empreendimentos por cooperação (horizontal).

Em pesquisa similar conduzida no Brasil, Dotto; Machado; Costa (2002) verificaram que 0 sucesso dessa forma de atuação requer o abandono do individualismo, ou seja, o empresário deve mudar sua atitude sobre a forma como gerencia seu negócio. A colaboração é uma premissa básica para o sucesso desse tipo de organização. Troca de informações nos diversos níveis; intercâmbio de idéias; desenvolvimento de uma visão estratégica única para o grupo; definição clara da área de atuação dos componentes; definição da forma de contribuição de cada um na manutenção das operações e a busca de soluções comuns para satisfazer todos os membros do grupo são pontos básicos para a manutenção do agrupamento de empresas.

Para Van Dijk; Sverrison (2003, p.187), é essencial que o agrupamento seja operacionalizado em termos de rede. Às vezes, é impossível fazer isso de forma rigorosa, mas a consideração qualitativa da conectividade social é superior aos conceitos baseados em suposições infundadas sobre as implicações das distribuições espaciais.

Os autores sugerem uma tipologia de agrupamentos de fabricantes em rede, baseada num grande número de estudos de casos publicados em antologias, jornais e em teses de Ph.D nos últimos 10 anos, conforme estudos por eles realizados. É o que se verifica no quadro 1.

\begin{tabular}{|c|c|c|c|}
\hline TIPO OU ESTÁGIO & INDICADOR OBSERVÁvEL & PRINCIPAL BENEFÍcIO OBSERVADo & DINÂMICA TÉCNICA \\
\hline Local & Proximidade das empresas & Troca de informações & Imitação \\
\hline Mercado local & Atividades principais similares & $\begin{array}{c}\text { Facilidade de acesso/ } \\
\text { competitividade }\end{array}$ & $\begin{array}{c}\text { Desenvolvimento de } \\
\text { produtos }\end{array}$ \\
\hline $\begin{array}{c}\text { Relacionamento } \\
\text { local }\end{array}$ & Divisão de trabalho & Especialização & Complementariedade \\
\hline $\begin{array}{c}\text { Inovadores } \\
\text { Distrito Industrial }\end{array}$ & $\begin{array}{r}\text { Incremento da co-operação } \\
\text { formal }\end{array}$ & Adaptabilidade & Engenharia reversa \\
\hline
\end{tabular}

\section{Quadro 1 - Tipologia da dinâmica dos agrupamentos e sua evolução.}

Fonte: Adaptado de Van Dijk e Sverrison (2003, p. 188)

Nos agrupamentos de local, o principal benefício observável é o fácil intercâmbio de informações que fluem das condições de espaço reduzido e proximidade. Pequenas empresas trabalhando em tais agrupamentos, às vezes, se saem melhor do que aquelas que operam em locais isolados. 
O agrupamento de mercado facilita 0 acesso do cliente, que poderá encontrar produtos similares em oferta e comparar preços. Da mesma forma, os fornecedores tendem a se localizar nas proximidades por razões de escala, ganho marginal, tempo e conveniência. Nesse tipo de agrupamento há grande concorrência, pela similaridade das atividades reunidas. Propriedades industriais, zonas de artesanato e mercados municipais são agrupamentos "formais" nos quais os empresários se reúnem e que têm o potencial de tornarem-se agrupamentos de mercados.

Os agrupamentos de relacionamento se caracterizam por uma divisão rudimentar de trabalho entre empresas. Os principais benefícios estão associados à especialização, na qual as empresas focarão uma ou mais atividades dentro de uma cadeia maior de produção. Nesse tipo de agrupamento, o dinamismo tecnológico - oriundo da especialização dos diversos componentes - gera um movimento de maior capacidade de inovação dentro do próprio grupo. Embora, individualmente, as empresas sejam auto-suficientes em seus respectivos processos de produção, vários serviços especializados como transporte e, em formas mais avançadas, serviços de contabilidade, encontram campo fértil para exploração, de forma que tais empreendimentos, chamados de complementares, também se beneficiem da escala e da proximidade de sua carteira.

Os agrupamentos inovadores produzem, no local, novidades que podem ser "exportadas" ou imitadas em outras regiões, a exemplo, empregando técnicas conhecidas em materiais disponíveis na área. O ganho com tais desenvolvimentos pode ser convertido em avanço competitivo em relação a outros agrupamentos e lugares. Isso viabiliza a venda dos produtos em outros locais ou regiões, ou mesmo em outros países. Em geral, as relações com mercados de outros lugares introduzem critérios diferentes de qualidade, o que pode ser instrumental na evolução do agrupamento, o qual pode ser considerados o primeiro passo em direção a industrialização.

Um distrito industrial eficiente é aquele composto por empresas com produtos relacionados ou similares, as quais desenvolveram fortes relacionamentos que facilitam a inovação e contribuem para uma maior eficiência. Neles, a cooperação é formalizada de maneira crescente, focada na infraestrutura de competência e física, nos esforços de marketing conjuntos, nos esquemas de controle de qualidade e outras tarefas similares. Para sua formação é preciso considerar três condições:

a) ambiente condutivo sócio-cultural, facilitando o reconhecimento e confiança mútuos;

b) comerciantes e outros agentes funcionam como agentes de estrutura dentro do agrupamento $\mathrm{e}$

c) governo local efetivo.

Essas condições não são sempre preenchidas, somente esperadas, o que, de certa forma, torna normativo o conceito de distrito industrial convencional.

Van Dijk; Sverrison (2003) continuam seu estudo demonstrando os mecanismos de transição e regressão entre os tipos de agrupamento por eles mencionados. Porém, para fins de estabelecimento de uma alternativa para a viabilização de um empreendimento de pequeno ou médio porte, num primeiro momento, bastam os conceitos elementares apresentados e discutidos até o momento para fins de reflexão.

Ao discutir a aplicabilidade dos conceitos aqui apresentados, deve-se ter em mente que, em países em desenvolvimento, a tendência da formação desse tipo de agrupamento, muitas vezes, ocorre em função de atividades sobreviventes de pessoas ou empresários sem recursos financeiros, sem acesso a mercados, com parcas habilidades para iniciar e administrar estabelecimentos industriais ou comerciais, dependendo do tipo de produto disponível. Como o desenvolvimento de agrupamentos se baseia em processos de inovação distribuída e gradual, sua adoção é uma opção para essa realidade, pois esse modelo impõe uma cooperação complexa entre pessoas e empresas. 
Em geral, nesse tipo de mercado, as estratégias de integração vertical são iniciadas e conduzidas por uma única empresa, sem a necessidade da manutenção de uma relação tão complexa. Como conseqüência, fica diminuído o poder de inovação da empresa que optou por essa alternativa e da própria economia e sociedade local.

Apesar das alternativas apresentadas induzirem a conclusão de que um caminho a ser seguido pelos governos é a adoção de políticas que levem em conta as oportunidades oferecidas pelas estratégias de integração vertical / horizontal e de desenvolvimento de agrupamentos, não é prático oferecer suporte a milhões de firmas de pequena escala por meio de custosas intervenções diretas em suas operações.

Ao se buscar informações sobre a posição dos governos em relação à criação de serviços de desenvolvimento de negócios, verifica-se que seus esforços tendem a ter impacto limitado, uma vez que o treinamento por eles oferecido é genérico, até pela complexidade e amplitude das atividades, de forma que, para serem viáveis, os conteúdos sobre negócios precisam ser padronizados. Um treinamento efetivo seria participante e focado, adequadamente monitorado e com base na recuperação dos custos, premissas aceitas e viáveis quando essa ação é iniciada por grupos de pessoas ou empresários interessados.

Ao atingirem estágios mais avançados, é comum que esses agrupamentos apresentem maior interação e participação em propostas governamentais. Dotto; Machado; Costa (2002) verificaram a formação de uma rede horizontal, ou seja, empresas de mesmo segmento se complementando. A troca de informações e a definição conjunta de estratégias em relação à produção, marketing, vendas, etc., bem como um grande espírito de colaboração entre os componentes, geraram um poder de alavancagem de negócios capaz de beneficiar às empresas individualmente e a seus fornecedores e clientes.

Tal prática, muito comentada, mas ainda pouco difundida no Brasil, se justificou pela própria globalização de mercados. Na impossibilidade das empresas, a todo o momento, desenvolverem novas tecnologias, novas formas de atuação e / ou de gestão, no intuito de se manterem competitivas, tal alternativa, mais do que uma opção, acabou se provando uma necessidade. Para empresas de pequeno e médio porte, tais demandas são muito onerosas e nem sempre viáveis quando tentadas individualmente.

Dotto; Machado; Costa (2002) consideraram, em seu trabalho, as experiências bem sucedidas de associação de pequenas empresas na Itália e na Alemanha, referências constantes em estudos econômicos que procuram explicar a pujança econômica de países que apresentam grandes índices de produtividade e crescimento econômico. Graças a esse tipo de estrutura, boa parte das exportações realizadas por esses países é feita por empresas de pequeno e médio porte, as quais, de outra forma, não conseguiriam apurar escala de produção, nem uma relação preço / custo competitivo.

Quando analisada a aplicabilidade dos conceitos aqui abordados, chega-se a conclusão de que, compreendendo que a união de pequenos e médios pode ter como resultado a superação das dificuldades a ponto de viabilizar as oportunidades apresentadas, chegar-se-á a conclusão de que mais do que uma opção, essa seria quase que uma questão de sobrevivência.

A afirmação feita anteriormente se baseia na realidade brasileira, principalmente, em relação ao acesso à infra-estrutura física, comercial e profissional, as barreiras à entrada no mercado e as políticas governamentais. Isoladamente, nem as grandes empresas podem ser capazes de resistir a essa realidade. Se o Brasil quer realmente criar condições para um crescimento econômico sustentado, os empreendedores produtivos devem unir esforços para serem capazes de superar o quadro de adversidades que se apresenta atualmente. 


\section{CONSIDERAÇÕES FINAIS}

Mais do que um movimento ou conceito econômico e social, o empreendedorismo é um sentimento que acompanha o ser humano desde as remotas eras. A história traz vários exemplos de ações empreendedoras na iniciativa privada e nas estruturas governamentais de países economicamente desenvolvidos. Seus líderes foram ou são empreendedores, conforme apresentado ao longo deste trabalho.

A inovação é um conceito amplo, que não remete obrigatoriamente a uma nova invenção. Em muitos casos, melhorias constantes acabam gerando ganhos tão relevantes quanto os obtidos por meio de um produto ou serviço inédito.

Quanto mais um empreendimento for motivado pela oportunidade, maior será a incidência de inovação. Pois, conforme se observou no decorrer deste trabalho, os empreendimentos motivados pela necessidade acabam copiando modelos existentes. Nesse caso, a possibilidade de fracasso é maior devido ao grau de dependência do empreendedor em relação ao empreendimento. Quanto maior a necessidade de retorno no curto prazo, maior o risco de insucesso para o empreendimento.

A pesquisa ainda revelou que a rede de relacionamento é um dos alicerces para empreendedores de qualquer parte do mundo. A possibilidade de trocar idéias, intercambiar conhecimentos e fomentar negócios entre conhecidos é um dos fatores que auxiliam os empreendedores na constituição e manutenção de seus negócios.

O agrupamento de pequenas e médias empresas propicia a estas um poder de competitividade e relevância no mercado capaz de suplantar os limites individuais de cada uma. Este trabalho procurou demonstrar que, para sobreviver e crescer, um empreendedor precisa considerar a possibilidade de abrir mão da individualidade, levando em conta os horizontes temporais que poderão lhe dar condições de buscar auxílio para que seu empreendimento floresça, cresça e gere frutos. O empreendedor deverá, também, aprender a trabalhar dentro de um contexto maior que, em última análise, será 0 mercado no qual estiver inserido.

\section{REFERÊNCIAS}

\section{APPOLINÁRIO, F. Dicionário de metodologia científica: um guia para a produção do} conhecimento. São Paulo, Atlas: 2004.

BAUMOL, W. J. Entrepreneurial cultures and countercultures. Academy of Management Learning and Education, 2004, Vol. 3, n. 3, pp. 316-326.

BEUREN, I. M. Como elaborar trabalhos monográficos em contabilidade: teoria e prática. São Paulo: Atlas, 2004.

CERVO, A. L.; BERVIAN, P. A. Metodologia científica. 5. ed. São Paulo: Prentice Hall, 2002.

DORNELAS, J. C. A. Empreendedorismo corporativo: como ser empreendedor, inovar e se diferenciar na sua empresa. Rio de Janeiro: Elvesier Editora Ltda, 2003.

DOTTO, D. M .R.; MACHADO, R. A; COSTA, L. C. Empreendedorismo e associativismo: a rede de metalúrgicas e serralharias. Anais, IV ENEMPRE - Encontro Nacional de Empreendedorismo, Escola Nacional de Empreendedorismo - ENE, Universidade Federal de Santa Catarina, UFSC: outubro, 2002 
GLOBAL ENTREPRENEURSHIP MONITOR (GEM). Empreendedorismo no Brasil: relatório global 2002. Global Entrepreneurship Monitor, 2002. Disponível em: http://www.sebrae.com.br/br/ued/download/relatorio_global_2002.pdf Acesso: 26 nov. 2004.

.Empreendedorismo no Brasil: relatório global 2003. Global Entrepreneurship Monitor, 2003. Disponível em: http://www.sebrae.com.br/br/ued/download/relatorio_global_2003.pdf Acesso: 26 nov. 2004.

GREVE, A.; SALAFF, J. Social networks and entrepreneurship. entrepreneurship, theory and practice, Fall, 2003, pp. 1-22.

MARCONI, M. A.; LAKATOS, E.M. Técnica de pesquisa. 4. ed. São Paulo: Atlas: 1999.

MENZIES, T. V.; DIOCHON, M. e GASSE, Y. Examining venture-related myths concerning women entrepreneurs. Journal of Developmental Entrepreneurship, Vol. 9,no. 2,August,2004, pp. 89-107.

PINTO, L. F. S. O Espírito empreendedor no processo estratégico. Revista Conjuntura Econômica. Fundação Getúlio Vargas: Rio de Janeiro, RJ, vol. 43, n. 12, pp. 61-63.

SCHUMPETER, J. A. Capitalism, socialism and democracy. London: Routledge, 1996.

TIESSEN, J. H. Individualism, collectivism, and entrepreneurship: a framework for international comparative... Journal of Business Venturing,Sep97,Vol. 12 Issue 5, pp.357-376.

VAN DIJK, M. P.; SVERRISSON, A. Enterprise clusters in developing countries: mechanisms of transition and stagnation. Entrepreneurship \& Regional Development, 15, July-September 2003, pp. 183-206.

\section{THE ENTREPRENEURSHIP AND THE ECONOMIC EVOLUTION OF THE NATIONS: IDEAS AND CONCEPTS FOR ITS SUCCESS IN BRAZIL}

Abstract: This article presents a comparative analysis between the data of the researchs carried by the Global Entrepreneurship Monitor (GEM) in 2002 and 2003, in special those relative to the entrepreneurship in Brazil, with international researchs. The main goal is to contribute for the better understanding of the brazilian enterprising movement, having as reference the international experiences, and to offer new approachs to be considered for potential lentrepreneurs. This is a exploratory, documentary, bibliographical, descriptive and qualitative research. In its begin it looks for to evidence that the entrepreneurship can be understood by the study of examples occurred throughout history. During the historical description the innovation concept is introduced as a basic element in the enterprising process. In the sequence, the work looks for to demonstrate, by means of the comparative analysis, some similarities between the brazilian enterprising process and what occurs in other countries, presents and it argues the concept of social networks as an instrument that helps to develop the enterprises, and finishes with the presentation of the concept of grouping of companies, its advantages and requirements for an efective implementation.

Key words: Entrepreneurship. Innovation. Social networks. Business grouping.

Submissão: julho de 2006 Aceite: novembro de 2006 